\title{
CARACTERIZAÇÃO MECÂNICA E ELÉTRICA DA LIGA 6101 MODIFICADA COM DIFERENTES TEORES DE MG
}

\author{
Ulysses Rodrigues Prazeres ${ }^{l}$ \\ W. L. R. Santos ${ }^{l}$ \\ E. S. Freitas ${ }^{l}$ \\ H. T. Costi ${ }^{1}$ \\ José Maria do Vale Quaresmal
}

\begin{abstract}
Resumo: $\mathrm{O}$ mercado de cabos de ligas de alumínio para transporte e distribuição de energia elétrica tem crescido bastante nos últimos anos graças à elevada resistência mecânica e peso reduzido desses cabos. $\mathrm{O}$ objetivo deste estudo é investigar a influência de diferentes teores de $\mathrm{Mg}$ na evolução microestrutural de uma liga da serie 6101 que é bastante empregada na transmissão e distribuição de energia elétrica, assim como analisar o seu efeito nas propriedades mecânicas e elétricas do material. As ligas utilizadas neste trabalho foram vazadas em um molde com formato de "U", para que fosse possível retirar corpos de provas cilíndricos. O teor de Si foi constante $(0,6 \%)$ e adicionado $\mathrm{Mg}$ nos teores de: 0,3; 0,5; 0,7; 0,9; 1,1\%. Esses corpos de prova foram usinados até $10 \mathrm{~mm}$ de diâmetro, laminados a frio até chegarem ao diâmetro de $3,98 \mathrm{~mm}$, e posteriormente submetido ao processo de trefilação para que finalmente chegassem ao diâmetro de 3,45 $\mathrm{mm}$. As ligas foram caracterizadas mecanicamente a fim de se avaliar as respostas das propriedades mecânicas do material (Limite de resistência à tração, alongamento e tenacidade) e eletricamente através de ensaios de condutividade elétrica. Os resultados obtidos mostraram, em alguns casos, que o aumento no teor de $\mathrm{Mg}$ contribuiu para elevar a resistência mecânica e diminuir a capacidade de conduzir energia elétrica.
\end{abstract}

Palavras-chave: Liga 6101, propriedades mecânicas, resistividade elétrica.

\begin{abstract}
Power cables are manufactured by aluminum alloys due to the mechanical resistance obtained and reduced weight. This paper shows the Mg content influence in 6101 alloy series, the microstructural development obtained to produce power cable, as well as the mechanical and electrical properties analyses in material. These alloys were cast into a "U" mold shape, to obtain cylindrical specimens. The Si content was constant (0.6\%) and $\mathrm{Mg}$ was added as following contents: $0.3 ; 0.5 ; 0.7 ; 0.9$ and $1.1 \%$. These specimens were machined to $10 \mathrm{~mm}$ diameter, cold rolled to $3.98 \mathrm{~mm}$ diameter and after drawn to $3.45 \mathrm{~mm}$ diameter, to obtain wires. The alloys were characterized by tension test to evaluate the mechanical properties of material (Tensile Strength, Elongation and Toughness), and by electrical resistivity test to evaluate electrical properties. The results show that when $\mathrm{Mg}$ content is increased, mechanical resistance can be elevated and electrical capacity decreased, on the researched alloys.
\end{abstract}

Keywords: 6101 alloy, mechanical properties, electrical resistivity.

1 Universidade Federal do Pará. 


\section{INTRODUÇÃO}

As ligas de alumínio são bastante utilizadas em diversas aplicações industriais, graças a sua elevada resistência e solidez. $\mathrm{O}$ cobre, o magnésio e o silício são alguns dos elementos que mais se prestam a formar liga com o alumínio por sua elevada solubilidade no mesmo.

A maior ou menor eficiência de um metal e de suas ligas em ser aplicado no processo de fundição/solidificação deverá estar associada a sua afinidade com o material do molde. Apesar das ligas fundidas de Al-Si, Al-Mg, Al-Mg-Si e Al-Si-Cu serem importantes comercialmente, os dados sobre fluidez, incluindo a influência das variáveis de fundição, precisam ser melhor avaliadas e, desta forma, importantes variáveis do processo de solidificação, como o grau de superaquecimento, a composição da liga e a afinidade metal/molde podem modificar a fluidez da liga e, a consequência desta modificação, sobre a estrutura produzida, necessita ser melhor investigado. Verran et al[1] em seus estudos além de apresentar uma breve revisão bibliográfica sobre a importância do conhecimento da fluidez metálica para emprego no processo de fundição enfoca, também, os efeitos do teor e do tipo de elemento de liga bem como da temperatura de vazamento sobre a fluidez do Alumínio e de algumas ligas de Alumínio.

Em seus estudos Kim e Loper[2] analisaram a fluidez das ligas Al-Si com variações de cobre até aproximadamente 3,5\%, para vários graus de superaquecimento e constataram que baixos teores de cobre afetam esta propriedade do binário, como pode ser visto na Fig.(1a) a seguir.

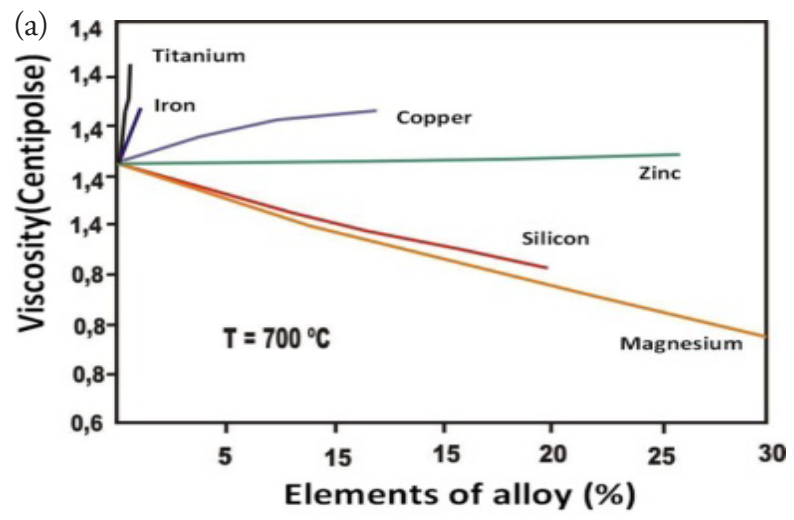

ENGEVISTA, V. 13, n. 2. p. 122-128, junho 2011

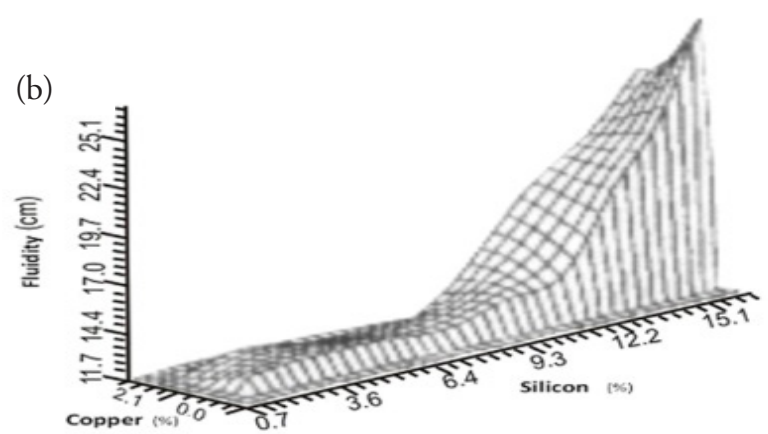

Figura 1 - (a)Influência dos elementos de liga na viscosidade do alumínio, Verran[1] e (b) na variação da fluidez do alumínio em função dos teores de silício e cobre, Kim e Loper[2]

A Fig.(1a) apresenta os gráficos que mostram a variação da viscosidade do alumínio com elementos de liga comum.

Pelo gráfico é possível observar que a viscosidade da liga decresce consideravelmente com aumento do teor de Si e de Mg. Por seu lado o cobre, mesmo em baixos teores, eleva esta propriedade.

No gráfico da Fig.(1b) pode ser avaliada a forte influência do $\mathrm{Mg}$ sobre a fluidez do alumínio o que já não acontece com o cobre.

Entretanto, para melhor entender-se da fluidez é necessário o conhecimento de uma importante propriedade dos metais fundidos: a viscosidade. Sobre este aspecto Wang [3] sugere que a variação da temperatura de solidificação, a viscosidade, a tensão superficial do metal e a soma da presença de inclusões são os maiores fatores que determinam a fluidez da liga. Apesar do alto ponto de fusão do Si em relação ao $\mathrm{Al}$ e da proximidade do ponto de fusão do $\mathrm{Mg}$ ao do $\mathrm{Al}$ estes dois elementos parecem afetar a viscosidade da liga, de forma idêntica, que decresce com o acréscimo do teor dos mesmos.

Segundo Loper[4] e Kim e Loper[5] este comportamento tem sido atribuído à influência do alto calor de fusão do silício pro-eutético, muito maior do que o do $\mathrm{Al}$ ou do $\mathrm{Mg}$, de modo que esta liberação intensa de calor durante a solidificação possibilita que as ligas com teores de silício mais elevados mantenham o estado líquido por mais tempo e assim molham melhor o molde. O modo de solidificação pode ser alterado para o crescimento de grão colunar com frente plana (caso das ligas diluídas) até a formação de dendri- 
tas colunares nas quais os braços são expostos e fraturam formando grãos equiaxiais (caso das ligas ricas em soluto) que fluem pela corrente de metal líquido.

Como exemplo podemos citar o trabalho de Mattos[6], no qual é sugerido que: $h_{i}$ maiores, provocam camadas sólidas espessas que aquecem o molde e se contraem suavemente e, influenciada pela pressão metalostática, geram Gap's menores provocando estruturas grosseiras (colunar) por serem produzidas com baixas Velocidades de Solidificações e baixas Taxas de Transferência de Calor que inibem o movimento convectivo intenso no metal líquido à medida que cresce o teor de soluto na liga, como fica evidente na Fig.2, na qual tem-se a macroestrutura da faixa central do lingote com as dimensões $[20 \times 60] \mathrm{mm}$.

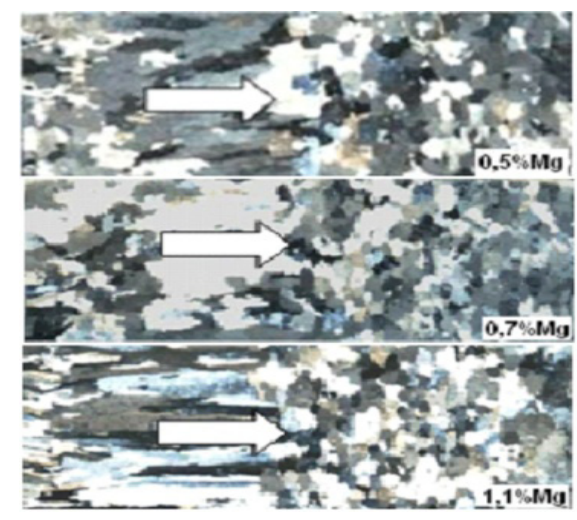

Figura 2 - Macrografias obtidas para as ligas $\mathrm{Al}-0,6 \% \mathrm{Si}-(0,5 ; 0,7$ e 1,1)\%Mg. Reagente Poulton, $5 \mathrm{~s}$.

$\mathrm{Na}$ Fig.2, é possível observar que à medida que o teor de $\mathrm{Mg}$ aumenta ocorre nítida mudança na forma da estrutura bruta de fusão, partindo de grãos colunares pequenos para colunares nitidamente alongados com evidente transição colunar/ equiaxial para todas as ligas à cerca de $28,9 \mathrm{~mm}$ da interface metal/molde, como ilustrado pelas setas.

A melhor molhabilidade do metal pelo molde pode ser associada à maior fluidez do metal ou da liga, e este aspecto pode ser associado ao "mushy zone" ou intervalo de solidificação ou faixa de solidificação que segundo Garcia[7] é identificada pela distancia das linhas "Liquidus/ Solidus" para cada teor da liga.

Para uma liga que possui um intervalo de solidificação curto, Fig.3, o mushy é mais fino e a casca sólida, que se forma sobre o menisco líquido nos instantes iniciais, é mais grossa, além disso, a força motriz para a distorção desta casca é mais forte e aumenta com o tempo. Força motriz para a distorção térmica mais a pressão metalostática agem de tal forma que somente a região mais fina (região suposta com menor resistência mecânica) da casca ou região do menisco seja empurrada em direção à parede do molde, promovendo a formação das marcas superficiais, com péssimos reflexos na trabalhabilidade do lingote, principalmente, à frio.

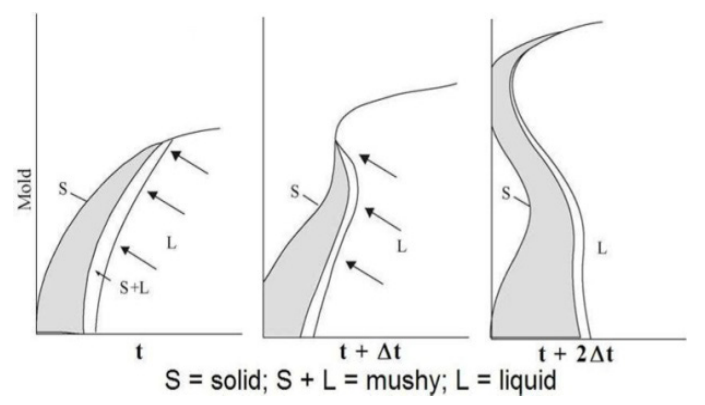

Figura 3 - Esquema ilustrativo da ação da pressão metalostática e da força motriz durante a solidificação de ligas com intervalo de solidificação curto ou baixa fluidez

Quando se tem uma liga com intervalo de solidificação longo, Fig.4, ter-se-á um "mushy” espesso. Isto implica em uma casca sólida mais delgada, que é menos resistente à pressão metalostática, resultando na compressão desta casca sólidas contra a parede do molde. Este fato evita a distorção térmica, inibindo a formação das marcas superficiais, com bons reflexos na trabalhabilidade do lingote.

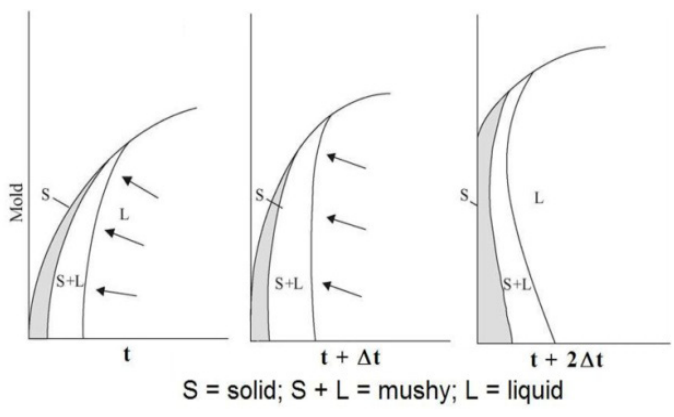

Figura 4 - Esquema ilustrativo da ação da pressão metalostática e da força motriz durante a solidificação de ligas com intervalo de solidificação longo ou alta fluidez

Desta forma constata-se que a maior fluidez é um atributo do metal ou liga metálica que lhe permite molhar melhor o molde e, como conse- 
quência, interferir no processo de geração da estrutura final do fundido, melhorando suas características de trabalhabilidade.

\section{MATERIAIS E MÉTODOS}

A composição química das ligas (Tab.1) possui uma formulação que possibilita tolerância de variação ampla para a produção e uso relativo de suas propriedades verificação da composição química da liga comercial de alumínio e das ligas com adição de $0,3 \%, 0,5 \%, 0,7 \%, 0,9 \%$ e $1,1 \%$ de $\mathrm{Mg}$ foram realizadas na Alubar Metais S/A utilizando espectrômetro de massa e os resultados obtidos para uma média de três análises é mostrada na Tab.2.

Tabela 1 - Composição química das ligas 6101 e 6201

\begin{tabular}{|c|c|c|c|c|}
\hline Elementos & $\mathrm{Si}$ & $\mathrm{Fe}$ & $\mathrm{Cu}$ & $\mathrm{Mg}$ \\
\hline 6101 & $0,3 \mathrm{a} 0,7$ & 0,5 & 0,1 & 0,33 a 0,8 \\
\hline
\end{tabular}

Tabela 2 - Composição química das ligas (\%)

\begin{tabular}{|c|c|c|c|}
\hline Ligas & Si & Mg & Al \\
\hline Al- $0,3 \% \mathrm{Mg}$ & 0,5935 & 0,3036 & 98,62 \\
\hline Al- $0,5 \% \mathrm{Mg}$ & 0,6235 & 0,4922 & 98,43 \\
\hline Al- $0,7 \% \mathrm{Mg}$ & 0,6152 & 0,6804 & 98,33 \\
\hline Al- $0,9 \% \mathrm{Mg}$ & 0,6039 & 0,9632 & 97,96 \\
\hline Al- $1,1 \% \mathrm{Mg}$ & 0,5749 & 1,0197 & 97,97 \\
\hline
\end{tabular}

As ligas foram preparadas por fundição utilizando alumínio comercial em cadinhos de grafita, em um forno tipo mufla, marca BRASIMET. As ligas foram vazadas fixando o teor de silício em 0,6\% e adicionando $\mathrm{Mg}$ nos teores de 0.3; 0,5; 0,$7 ; 0,9 ; 1,1 \%$, em um molde com o formato de "U”, para que fosse possível retirar corpos de prova cilíndricos. Esses corpos de prova foram usinados até $10 \mathrm{~mm}$ de diâmetro. Após a usinagem os mesmos foram laminados a frio, em um laminador duo elétrico com canal circular, sendo feitos sucessivos passes até chegarem a fios de aproximadamente $3,90 \mathrm{~mm}$ de diâmetro e posteriormente foram trefilados até o diâmetro de $3,45 \mathrm{~mm}$.

A Fig. 5 apresenta uma sequencia na qual estão ilustrados os projetos do molde, $\mathrm{o}$ ato do vazamento e do desmoldar para a retirada do perfil obtido.

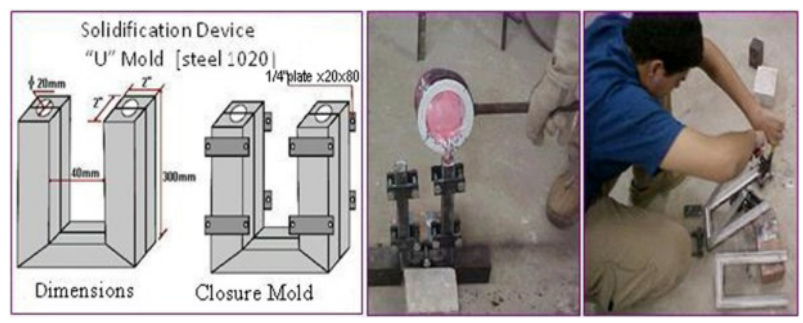

Figura 5 - Sequencia ilustrativa das operações para a obtenção do perfil "U"

Os perfis "U" obtidos como mostrado na Fig.5, depois de desmoldados passam por uma sequencia de operações de mudança de forma até o fio com o diâmetro final desejado, como mostra a Fig.6.

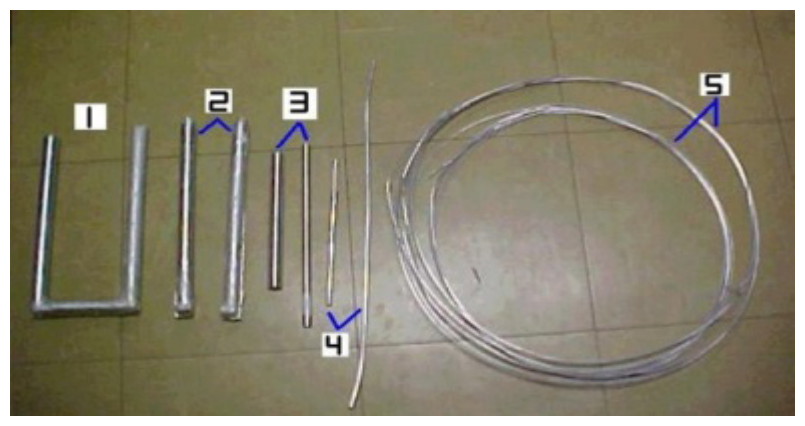

Figura 6 - Sequencia alto explicativa das etapas operacionais até a obtenção do diâmetro desejado de $3,45 \mathrm{~mm}$

Após este processo de deformação os corpos de provas foram submetidos ao ensaio de Resistividade Elétrica e Tração segundo a norma NBR5384; NBR 5285 e NBR-6207 respectivamente.

A análise das macrografias das fraturas após ensaios de tração foi feita em um (MEV) microscópio eletrônico de varredura LEO, modelo $1450 \mathrm{VP}$, as amostras a serem examinadas no MEV foram limpas com uma solução de álcool+acetona (PA) em um limpador ultrassônico por $10 \mathrm{~min}$. As amostras foram caracterizadas utilizando analises macroscópicas, e as macrografias do fundo do molde "U" onde foram analisados em um microscópio óptico modelo LEICA.

\section{RESULTADOS E DISCUSSŌES}

O conceito de trabalhabilidade preconizado por Dieter [8] que associa a boa deformabilidade a ausência de defeitos superficiais, precisa ser ampliado com a sequencia "endurecendo o 
material sem fragilizá-lo”. Nas observações feitas neste trabalho, tem-se que na etapa de usinagem de $20 \mathrm{~mm}$ para $10 \mathrm{~mm}$, já não se percebe evidências de porosidade, agente importante na avaliação qualitativa, quando se trata com ligas de alumínio. Além disso, na proporção em que se provoca a deformação a frio, inicialmente por laminação e posteriormente por trefilação, consegue-se chegar ao diâmetro $3,45 \mathrm{~mm}$ atendendo a norma NBR 5285.

Nos ensaios de tração foram observados os valores de alongamento e tensão de ruptura, uma vez que a perda de resistência mecânica para cabos é mais crítica que a perda de outras características.

A caracterização da fratura do ternário Al$-0,6 \% \mathrm{Si}-[0,3 ; 0,5 ; 0,7 ; 0,9 ; 1,1] \% \mathrm{Mg}$, foi realizada nos corpos de prova trefilados até o diâmetro de 3, $45 \mathrm{~mm}$, tendo por finalidade observar a ação do Mg quanto ao ganho nas propriedades mecânicas nos percentuais estudados.

O módulo de tenacidade foi calculado para avaliar a absorção de energia por unidade de volume sem ruptura da liga, e gerar dados que possibilitem direcionar a utilização das ligas em possíveis situações de serviço e aplicações nas quais forem submetidas, pela equação:

$\mathrm{U}=\left(\frac{\sigma_{\mathrm{R}}+\sigma_{\mathrm{E}}}{2}\right) \cdot \varepsilon_{\mathrm{F}}$

Onde $U$ é a tenacidade, $\sigma_{\mathrm{R}}$ é a tensão de ruptura, $\sigma_{\mathrm{E}}$ é a tensão de escoamento e $\varepsilon_{\mathrm{F}}$ é a deformação final.

Os ensaios elétricos realizados obedeceram à norma NBR 6814/1985. Após a obtenção desses resultados, foi necessária a correção da temperatura do ensaio para temperatura ambiente a $20^{\circ} \mathrm{C}$. Em seguida, o cálculo de resistividade elétrica é realizado, segundo a norma NBR 6815/1981.

\subsection{RESULTADOS MECÂNICOS}

A Fig.7 apresenta os resultados dos valores do Limite de Resistência a Tração (LRT). Observa-se que, na proporção que se aumenta a quantidade de Magnésio na liga, os corpos de prova apresentaram valores crescentes para esta propriedade mecânica segundo a equação gerada pela analise dos resultados obtidos.

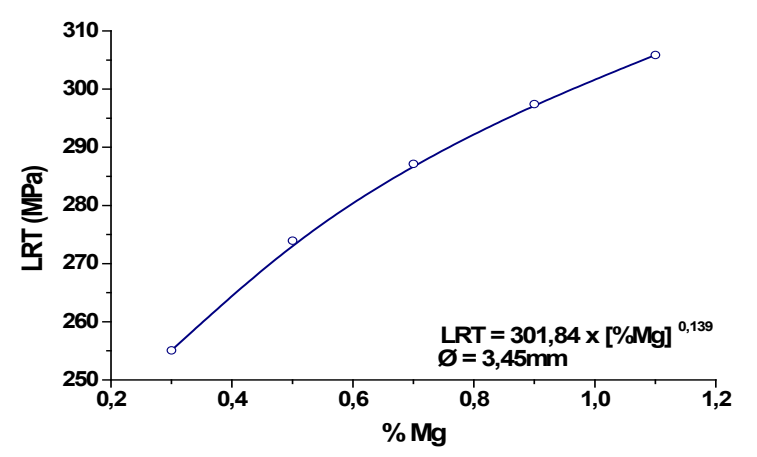

\section{Figura 7 - Limite de Resistência a Tração em Função do teor de Mg}

Pela descrição da curva apresentada na Fig. 8 é possível constatar que a capacidade de alongamento diminui com o acréscimo do teor de magnésio. Característica esta não apenas atribuída ao teor de soluto, mas também resultado do endurecimento provocado pelo processo de conformação - laminação e trefilação - a qual a liga foi submetida.

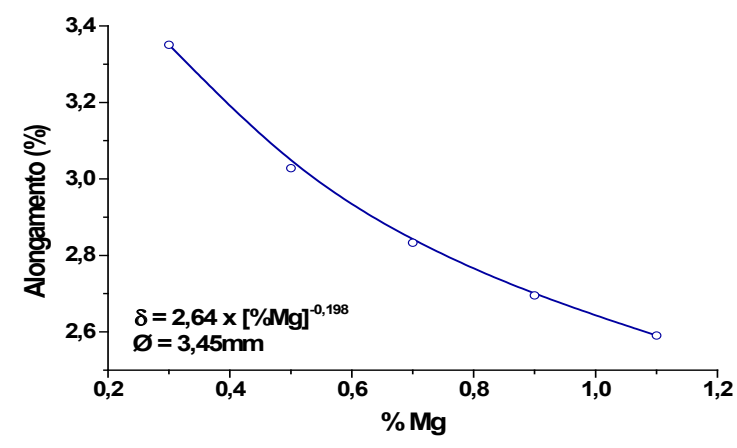

Figura 8 - Alongamento em Função do teor de Mg

A Fig.9 apresenta a evolução do módulo de tenacidade para a liga da serie 6101 modificada com diferentes teores de Mg. Pelo comportamento da curva e possível verificar um ganho de resistência mecânica da liga, uma vez que o modulo de tenacidade aumenta na proporção em que é adicionado o teor de Magnésio. Segundo Norton [9], um material dúctil com resistência a tração semelhante à de um frágil será muito mais tenaz. Tal alegação nos possibilita dizer que para esta liga o acréscimo do soluto (Magnésio) provoca uma maior absorção de energia antes que ocorra a fratura do material, pois a liga em estudo com maiores proporçôes de $\mathrm{Mg}$ se apresenta com um limite de resistência a tração próxima a de alguns aços, entretanto as suas macro fraturas não demons- 
tram uma perda tão acentuada na sua ductilidade. Como é mostrado posteriormente nas macrofractografias (Fig. 12).

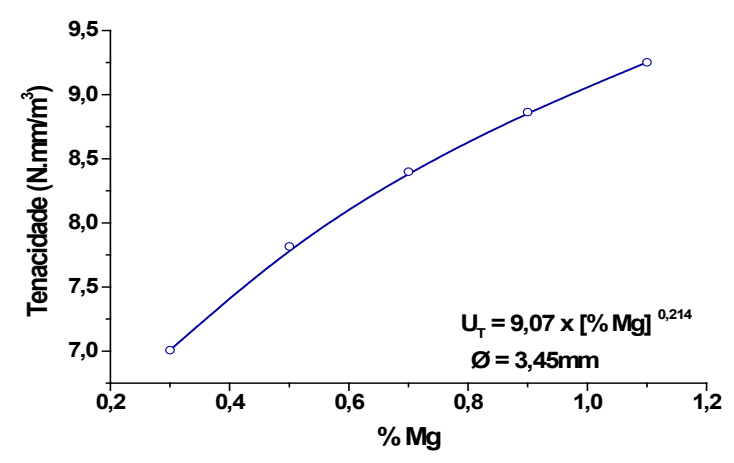

Figura 9 - Módulo de tenacidade em função do teor de $\mathrm{Mg}$

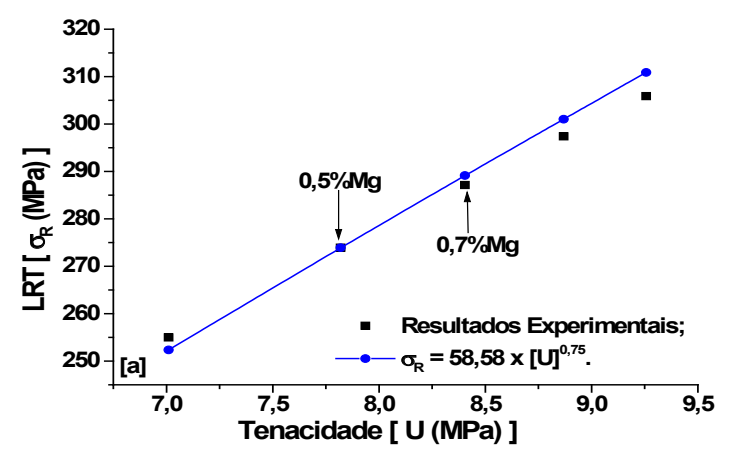

Figura 10 - Limite de Resistência a Tração em função do Módulo de tenacidade

\subsection{RESULTADO ESTRUTURAL}

Outra observação que pode ser feita diz respeito ao aspecto da macro que apontam uma mescla de grãos coquilhados e colunares menores até o limite $0,7 \% \mathrm{Mg}$ quando passam a crescer até tornarem-se pronunciadamente colunares. $\mathrm{Na}$ Fig. 12 pode ainda ser observado que as Micro Fraturas apresentam aspecto de ocorrência transgranular com as micro cavidades bem definidas.
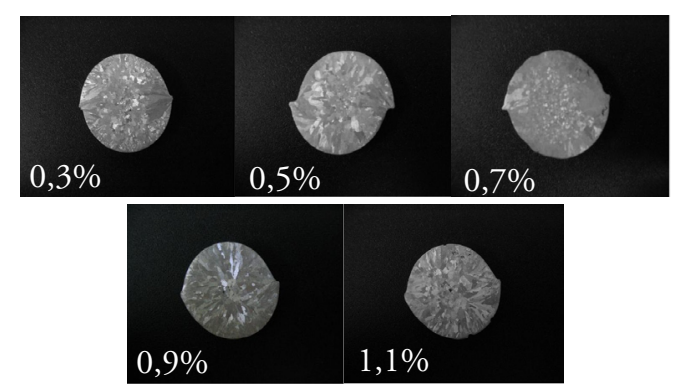

Figura 11 - Macrografias das ligas mostrando os grãos
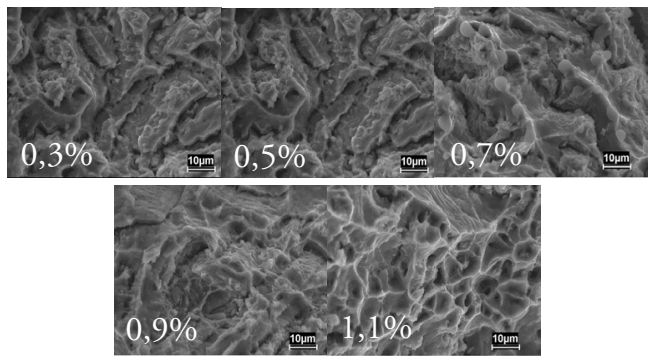

Figura 12 - Factografias das ligas mostrando as microcavidades

\subsection{RESULTADO ELÉTRICO}

As figuras 10 e 13 mostram o LRT e valores de condutividade elétrica em função da tenacidade, respectivamente. Estes resultados estão associados a estruturas macro e micro obtidos (Figs. 11 e 12). Ele observa que, quando a tenacidade aumenta o LRT também aumenta, estes resultados estão associados à perda de condutividade elétrica em \%IACS (International Annealed Copper Standard). Os valores mostram que o melhor teor de $\mathrm{Mg}$ para as propriedades mecânicas e elétricas, são $0,5 \%$ e $0,7 \%$.

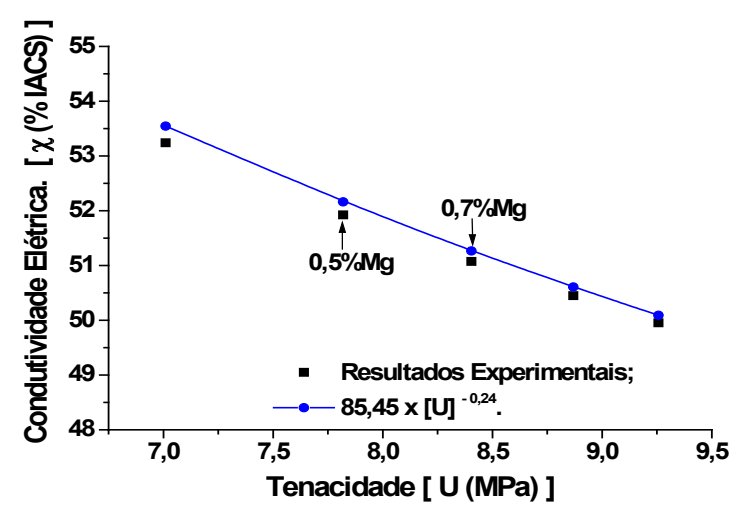

Figura 13 - Condutividade Elétrica em função da Tenacidade

\section{CONCLUSÓES}

Os resultados das propriedades mecânicas das ligas da série 6000 mostraram que os teores de $0,5 \%$ e $0,7 \% \mathrm{Mg}$ foram os mais promissores quando adicionados na liga binária Al-0,6\%Si. Estes resultados também melhoraram a performance para transmissão e distribuição de energia elétrica, porque combinam tamanho de grão com o alongamento, a tenacidade e o LRT, de acordo com a norma NBR 5285/2010. 


\section{AGRADECIMENTOS}

Os Autores agradecem o apoio recebido para o sucesso desta tarefa a Universidade Federal do Pará, ELETRONORTE e a ALUBAR METAIS S/A.

\section{BIBLIOGRAFIA}

[1] Verran, G. O., Paloshi Jr. J., Araujo Neto, E. (2004). Método Alternativo para Medição do índice de Fluidez de Ligas de $\mathrm{Al}$ em Coquilhas. Fundição e Serviços, no 134, 70-79.

[2] Kim, J. M. E, Loper, D. R. Jr. (1995). Effect of Solidification Mechanism on Fluidity of Al-Si Casting Alloys. AFS Transaction, no 95, 521-529.

[3] Wang, L., Maklouf, M., Apelian, D. (1995). Aluminium die casting alloys: alloy composition, microstructure, and properties-performance relationships. International Materials Reviews, v.40, no 6, 221-237.

[4] Loper, D. R. Jr. (1992). Fluidity of aluminumsilicon casting alloys. Trans. Amer. Foundrym. Soc. no 100, 533-538, 1992.
[5] Kim, J. M. E, Loper, D. R. Jr. (1999). A Influência da Solidificação sobre a Fluidez das Ligas de Alumínio-Silício. Fundição e Serviços, no 75, 14-28.

[6] Mattos, P. R. O. (2004). Desenvolvimento de Composição de Ligas Diluídas Al-Mg-Si com variação do Magnésio para Determinação da Trabalhabilidade. Dissertação (Mestrado em Engenharia Mecânica) - Universidade Federal do Pará.

[7] Quaresma, J. M. V., Cheung, N., Garcia, A. (2006). The effect of solidification thermal variables on surface quality of $\mathrm{Al}-\mathrm{Cu}$ ingots. Journal of Alloys and Compounds, 428, 130-138.

[8] Dieter, G. E. (1981). Metalurgia Mecânica. Ed. Guanabara Dois, 2a Edição.

[9] Norton, R. (2004). Projeto de Máquinas: uma abordagem integrada. Ed. Bookman, 2a Edição. 